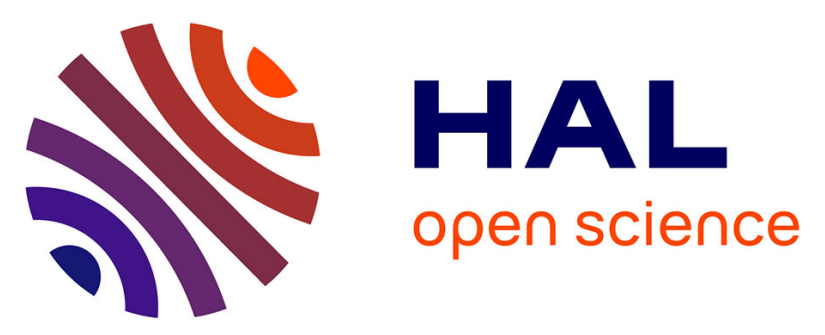

\title{
Calcium, Barium and Strontium apatites: A new generation of catalysts in the Biginelli reaction
}

Sana Ben Moussa, Jalel Lachheb, Michel Gruselle, Birgit Maaten, Kadri Kriis, Tõnis Kanger, Kaia Tõnsuaadu, Béchir Badraoui

\section{- To cite this version:}

Sana Ben Moussa, Jalel Lachheb, Michel Gruselle, Birgit Maaten, Kadri Kriis, et al.. Calcium, Barium and Strontium apatites: A new generation of catalysts in the Biginelli reaction. Tetrahedron, 2017, 73 (46), pp.6542-6548. 10.1016/j.tet.2017.09.051 . hal-01614924

\section{HAL Id: hal-01614924 \\ https: / hal.sorbonne-universite.fr/hal-01614924}

Submitted on 11 Oct 2017

HAL is a multi-disciplinary open access archive for the deposit and dissemination of scientific research documents, whether they are published or not. The documents may come from teaching and research institutions in France or abroad, or from public or private research centers.
L'archive ouverte pluridisciplinaire HAL, est destinée au dépôt et à la diffusion de documents scientifiques de niveau recherche, publiés ou non, émanant des établissements d'enseignement et de recherche français ou étrangers, des laboratoires publics ou privés. 


\title{
Calcium, Barium and Strontium Apatites: A New Generation of Catalysts in the Biginelli Reaction
}

Sana Ben Moussa ${ }^{\mathrm{a}}$, Jalel Lachheb ${ }^{\mathrm{a}}$, , Michel Gruselle*b ${ }^{\mathrm{b}}$, Birgit Maaten ${ }^{\mathrm{c}}$, Kadri Kriis $^{\mathrm{d}}$, Tõnis Kanger ${ }^{\mathrm{d}}$, Kaia Tõnsuaadu ${ }^{\mathrm{e}}$ and Béchir Badraoui ${ }^{\mathrm{a}}$

${ }^{a}$ U.R. Matériaux et synthèse organique UR 17ES31, Institut Préparatoire aux Etudes d'Ingénieurs de Monastir, Université de Monastir, 5019 Monastir, Tunisia

${ }^{b}$ CNRS, UMR 8232, Institut Parisien de Chimie Moléculaire, F-75005 Paris, France; Sorbonne Universités, UPMC Univ. Paris 06, UMR 8232, Institut Parisien de Chimie Moléculaire, F-75005 Paris, France

${ }^{c}$ Department of Energy Technology, Tallinn University of Technology Ehitajate tee 5, Tallinn 19086, Estonia

${ }^{d}$ Department of Chemistry and Biotechnology, Tallinn University of Technology, Akadeemia tee 15, 12618 Tallinn, Estonia;

${ }^{e}$ Laboratory of Inorganic Materials, Tallinn University of Technology, Ehitajate tee 5, 19086 Tallinn, Estonia

Keywords: Biginelli reaction, Hydroxyapatite, Modified hydroxyapatite, Catalysis

*corresponding author Tel. + 33144273090

e-mail: michel.gruselle@upmc.fr

\begin{abstract}
We describe herein the use of Calcium, Barium and Strontium hydroxyapatites (CaHAp, BaHAp and SrHAp) as well as CaHAp containing Magnesium, Copper, Zinc and Palladium (MgHAp, CuHAp, ZnHAp and PdHAp) as catalysts in the Biginelli reaction. The efficiency of CaHAp and SrHAp is very low, leading to the expected 3,4-dihydropyrimidin-2(1H)-one in poor yields. Mixed $\mathrm{Ba}_{5} \mathrm{Sr}_{5} \mathrm{HAp}_{\mathrm{A}}$ and $\mathrm{Ba}_{10} \mathrm{HAp}$ show interesting catalytic properties, especially $\mathrm{Ba}_{10} \mathrm{HAp}$ leading to pure isolated reaction products in good yields. The use of modified CaHAp seems to be of interest in regard to the yield obtained. Nevertheless the release of $\mathrm{Mg}, \mathrm{Cu}, \mathrm{Zn}$ and $\mathrm{Pd}$ ions in the solution during the catalytic process makes the use of such modified apatites less effective.
\end{abstract}

\section{Introduction}

Apatites, mostly hydroxyl- and fluorapatites are materials of considerable interest in a large research area [1, 2], including for catalytic applications. Some reviews are devoted to describe their efficiency as catalysts [3-6]. Among these catalytic properties, the C-C bond formation is of first importance in organic synthesis [7]. Pursuing our research in this area we report the use and efficiency of calcium, barium, and strontium hydroxyapatites as catalysts in the Biginelli reaction. 
The Biginelli reaction is an one pot three components coupling reaction between an aldehyde (1), a 1,3-dicarbonyl compound (2) and urea (3), affording 3,4-dihydropyrimidin-2(1H)-one (Scheme 1). This reaction was discovered by Pietro Biginelli in $1891[8,9]$.

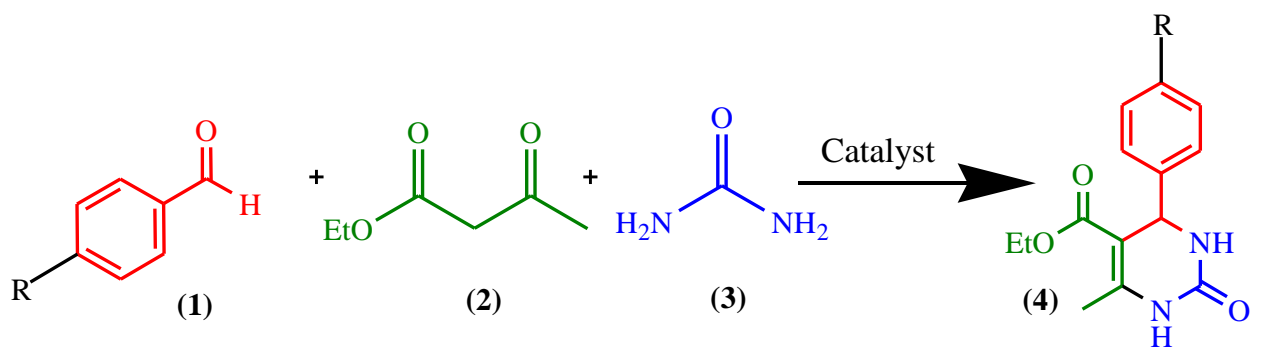
4a) $\mathrm{R}=\mathrm{H}$
4b) $\mathrm{R}=\mathrm{OCH}_{3}$
4c) $\mathrm{R}=\mathrm{N}\left(\mathrm{CH}_{3}\right)_{2}$
4d) $\mathrm{R}=\mathrm{NO}_{2}$
4f) $R=F$

Scheme 1. The Biginelli reaction: One pot synthesis of 3,4-dihydropyrimidinones

Originally, the Biginelli reaction was carried out by refluxing a mixture of the benzaldehyde, ethyl acetoacetate and urea in ethanol in the presence of $\mathrm{HCl}$ as catalyst. The process has been improved significantly over the years and several examples of this reaction were reported with high product yields using different catalysts and ligands [10-12]. The influence of polar and non-polar solvent has also been studied [13].

These compounds, also called "Biginelli compounds", have attracted attention as important structural motifs in medicinal chemistry because of their significant biological activities, such as antiviral, antimicrobial, antitumor, antibacterial, and anti-inflammatory properties [14,15]. Many of them are pharmacologically used as potent calcium channel blockers, antihypertensive agents, and neuropeptide antagonists [16].

Other efficient heterogeneous catalysts have been reported for the Biginelli reaction [17-19], they have all in common an acidic nature. Contrary to acidic catalysts there are only a few papers describing basic catalysts [20].

The mechanism of the Biginelli reaction, using acidic Brönsted or Lewis catalysts, was discussed by several authors $[13,21,22]$. Kappe [23, 24], re-examining this question concluded that the first step in this mechanism:" involves the acid-catalysed formation of an $\mathrm{N}$-acyliminium ion precursor from and aldehyde and urea component". 
Conditions that support the formation and reaction of $\mathrm{N}$-acyliminium ion provide one route to improving the Biginelli reaction.

Since it is important to produce less chemical waste and to strive towards greener chemistry, there are several examples of solvent-free reaction conditions using different types of catalysts [25-27]. They all have in common a slight excess of urea and a catalyst loading of less than $10 \%$ mol. Some examples of modified and non-modified apatite-catalysed Biginelli reactions can be found in the literature. The use of a Bi- and Na-modified HAp in neat conditions results in high isolated yields of the product (70\%) in half an hour [28]. It has also been shown that non-modified hydroxy- and fluorapatites are less active than modified apatites for the Biginelli reaction in refluxing toluene [29, 30]. For example, modified apatites with Lewis acids $\left(\mathrm{ZnCl}_{2}, \mathrm{CuCl}_{2}, \mathrm{CoCl}_{2}\right.$ and $\left.\mathrm{NiCl}_{2}\right)$ have a better catalytic activity and lead to isolated yields up to $90 \%$. However, the leaching of the metal is often a resulting problem.

Hydroxyapatite $\mathrm{Ca}_{10}\left(\mathrm{PO}_{4}\right)_{6}(\mathrm{OH})_{2}(\mathrm{HAp})$ is a mineral and its surface of which has acidic $\left(\mathrm{Ca}^{2+}\right.$, $\left.\mathrm{PO}_{2} \mathrm{H}\right)$ and basic $\left(\mathrm{OH}^{-}, \mathrm{PO}_{4}{ }^{3-}\right)$ sites [31]. Due to its diverse properties, it can be used as a heterogeneous catalyst for various reactions, such as Knoevenagel condensation [32], Diels-Alder reaction [33], Friedel-Crafts reaction [34], oxidation of propargylic alcohols [34], aldol reaction [36]. We have previously shown its application in Michael addition [37] and Glaser coupling reactions [38]. The catalytic activity of apatite can be modified by partial replacement of $\mathrm{Ca}^{2+}$ ions with other cations, including $\mathrm{Zn}^{2+}, \mathrm{Cu}^{2+}, \mathrm{Co}^{2+}, \mathrm{Ru}^{3+}, \mathrm{Pd}^{2+}$, and $\mathrm{La}^{3+}$ [39-44]. Increased reactivity of metal-modified apatite is often reached but the recovery of the catalyst is less convenient because of the potential leaching of metallic cations in the solution.

\section{Results and discussion}

First, we examined the catalytic effect of various apatites on the Biginelli reaction. A mixture of aldehyde (1), ethyl acetoacetate (2), urea (3) and catalyst (Scheme 1) was stirred over a period of time mentioned in Table 1. The experiment was performed at reflux conditions in the presence of different solvents. The reaction conditions and the results obtained can be seen in Table 1 .

We studied the influence of solvents on the HAp-catalysed Biginelli reaction (Table 1). The reaction between benzaldehyde (1), ethyl acetoacetate (2) and urea (3) afforded dihydropyrimidinone (4) in the presence of 10 mol\% of catalyst. The apatites HAp1, HAp2 and HAp3, HAp4 used for the reaction differ from each other in terms of their specific surface area (SSA), which depends on the synthetic method used for their preparation (see experimental 4.2.1). 
Table 1. HAp-catalysed Biginelli reaction in different solvents

\begin{tabular}{|c|c|c|c|c|c|c|}
\hline Entry & $\begin{array}{l}\text { Ratio of } \\
1: 2: 3\end{array}$ & Solvent & Catalyst & $\begin{array}{l}\text { Temp } \\
\left({ }^{\circ} \mathrm{C}\right)\end{array}$ & $\begin{array}{l}\text { Time } \\
\text { (d) }\end{array}$ & Yield $^{\mathrm{a}}(\%)$ \\
\hline 1 & $1: 1.2: 1.5$ & $\mathrm{MeOH}$ & HAp $1^{b}$ & 65 & 4 & 4 \\
\hline 2 & $1: 1.2: 1.5$ & THF & HAp $1^{\text {b }}$ & 66 & 3 & 10 \\
\hline 3 & $1: 1.2: 1.5$ & Water & HAp $1^{b}$ & 100 & 2 & - \\
\hline 4 & $1: 1: 3$ & Toluene & HAp $1^{b}$ & 80 & 3 & 10 \\
\hline 5 & $1: 1: 3$ & Toluene & $\mathrm{CuHAp}^{\mathrm{c}}$ & 80 & 3 & 40 \\
\hline 6 & $1: 1: 3$ & Toluene & $\mathrm{ZnHAp}^{\mathrm{d}}$ & 80 & 3 & 20 \\
\hline 7 & $1: 1: 3$ & Toluene & PdHAp $2^{d}$ & 80 & 3 & 65 \\
\hline 8 & $1: 1: 1$ & Toluene & $\mathrm{MgHAp}^{\mathrm{e}}$ & 80 & 3 & 35 \\
\hline 9 & $1: 1: 1$ & Ethanol & $\mathrm{MgHAp}^{\mathrm{e}}$ & 80 & 2 & 20 \\
\hline
\end{tabular}

${ }^{\mathrm{a}}$ Isolated yield of $4 .{ }^{\mathrm{b}} \mathrm{SSA}$ of the catalyst $82.3 \mathrm{~m}^{2} / \mathrm{g} .{ }^{\mathrm{c}} \mathrm{SSA}$ of the catalyst $77.7 \mathrm{~m}^{2} / \mathrm{g} .{ }^{\mathrm{d}} \mathrm{SSA}$ of the catalyst $109 \mathrm{~m}^{2} / \mathrm{g},{ }^{\mathrm{e}} \mathrm{SSA}$ of the catalyst $20 \mathrm{~m}^{2} / \mathrm{g}$.

Using HAp as catalyst, the reaction was extremely slow when refluxing methanol. The isolated yield of dihydropyrimidinone 4 after four days was only $4 \%$ (Table 1, entry 1). In THF the yield was only slightly higher (Table 1, entry 2 ) and no reaction occurred in water (Table 1, entry 3 ). Upon changing the ratio of the starting material to 1:1:3 and using toluene as solvent, an isolated yield of $10 \%$ was obtained after three days (entry 4). These results revealed that non-modified HAp1 is not a suitable catalyst for the Biginelli reaction in protic and aprotic, as well as in polar and nonpolar solvents.

According to the Brönsted acid or Lewis catalytic pathway mechanisms [13] the inefficiency of calcium apatite is not very surprising. As it is well known, apatite surfaces possess basic sites, namely $\mathrm{OH}^{-}$and $\mathrm{PO}_{4}{ }^{3-}$ and acidic ones, $\mathrm{Ca}^{2+}$ and $\mathrm{POH}$ acting as Lewis and Brönsted acidic centres respectively $[31,32]$. If their specific activity is low, it increases during acid-base catalysis as it is the case in the Michael reaction [37].

Sebti et al. have shown that the use of metal halide modified hydroxyapatites or fluoroapatites $[29,30]$ as catalysts for the Biginelli reaction in toluene increases the yield of the product up to $90 \%$. In this case, the catalyst is the Lewis acid metallic salt supported by the apatite and not the apatite itself.

Buvaneswari et al [28] have replaced $\mathrm{Ca}^{2+}$ by the couple $\mathrm{Na}^{+}-\mathrm{Bi}^{3+}$ and observed that the catalytic activity is better by introducing a highly charged ion $\mathrm{Bi}^{3+}$ into the apatitic lattice, which then in turn enhances the acidic character of the material. 
According to these results, hydroxyapatites with different $\mathrm{Cu}^{2+}, \mathrm{Zn}^{2+}, \mathrm{Pd}^{2+}$ and $\mathrm{Mg}^{2+}$ cationic substitutions were tested in the Biginelli reaction (Table 1, entries 5-7). These cations were chosen since they are better Lewis acids than $\mathrm{Ca}^{2+}$ due to a smaller ionic radius (IR) as it is shown in Table 2.

Table 2. Ionic radii for the $\mathrm{Ca}^{2+}, \mathrm{Cu}^{2+}, \mathrm{Zn}^{2+}, \mathrm{Pd}^{2+}$ and $\mathrm{Mg}^{2+}$ cations [45]

\begin{tabular}{l|lllll}
\hline Cations & $\mathrm{Ca}^{2+}$ & $\mathrm{Cu}^{2+}$ & $\mathrm{Zn}^{2+}$ & $\mathrm{Pd}^{2+}$ & $\mathrm{Mg}^{2+}$ \\
\hline Ionic radius (IR) In ( & 1.0 & 0.73 & 0.74 & 0.86 & 0.72 \\
\hline
\end{tabular}

The best results were obtained when using Pd-modified HAp2 (an isolated yield of 65\%, entry 7). Unfortunately leaching of the $\mathrm{Pd}$-ions was observed. The molar ratio of $\mathrm{Pd} / \mathrm{Ca}$ in the catalyst before and after the reaction was 0.24 and 0.14 respectively (detected by energy-dispersive X-ray spectroscopy). The next best result was obtained with CuHAp3 (40\%, Table 1, entry 5) and the use of ZnHAp2 did not lead to high yields (20\%, Table1, entry 6).

The yields obtained in this paper were lower than those described by Sebti et al [29]. However, there was a substantial difference in the process of modifying the apatite catalyst. Sebti et al mixed a water solution of a metal salt with apatite and water was evaporated. This approach does not exclude catalysis by Lewis acids that were not incorporated into the apatite structure. In our case nonincorporated metal salts were washed out with water and the only metal ions present were those in the apatite structure $[46,47]$. Although metal-modified apatites had higher catalytic activity than nonmodified hydroxyapatite the reaction rate remained slow. Next, a solvent-free apatite-catalysed Biginelli reaction was studied (Table 3).

Table 3. Solvent-free Biginelli reaction ${ }^{\mathrm{a}}$

\begin{tabular}{llll}
\hline Entry & Catalyst & Time(h) & ${\text { Yield }(\%)^{\mathrm{b}}}^{\text {(h) }}$ \\
\hline 1 & HAp3 & 5 & 50 \\
2 & CuHAp3 & 5 & 70 \\
3 & HAp3 & 24 & 85 \\
4 & CuHAp3 & 24 & 85 \\
\hline
\end{tabular}

${ }^{a}$ Reaction conditions: benzaldehyde 1 ( 1 equiv.), ethyl acetoacetate $\mathbf{2}$ (5 equiv.), urea $\mathbf{3}$ (1 equiv.), catalyst (10 mol\%), $80{ }^{\circ} \mathrm{C} .{ }^{\mathrm{b}}$ Isolated yield of 4 .

A considerable increase in the reaction rate was observed in solvent-free conditions. When carrying the reaction out neat, after half an hour, the reaction mixture thickened which indicated that the product was forming rapidly. Therefore, an excess of ethyl acetoacetate 2 was used to keep the mixture in a liquid phase. As these results were promising, as a next step, non-modified and $\mathrm{Cu}-$ modified apatites were investigated as catalysts. The isolated yield of product $\mathbf{4}$ in the presence of HAp3 was 50\% after 5 h (Table 3, entry 1). When using CuHAp3, the isolated yield was higher (70\%, 
Table 3, entry 2). It shows that higher isolated yields of the product can be obtained by modifying the hydroxyapatite with $\mathrm{Cu}$. However, under these harsh conditions leaching of the metal was detected. According to the atom absorption spectroscopy measurement results, the concentration of copper ions in apatite was reduced (before the reaction $4.1 \%$ and after the reaction $3.2 \%$ of $\mathrm{Cu}$ ). When the reaction time was increased to $24 \mathrm{~h}$, the isolated yields of the product in the presence of unmodified HAp3 and $\mathrm{Cu}$-modified HAp3 increased only by $35 \%$ and $15 \%$ respectively, resulting in an isolated yield of $85 \%$ in both cases (Table 3, entry 3 and 4). Thus, there is no need to use Cu-modified apatite for the Biginelli reaction in solvent-free conditions. Isolation of product $\mathbf{4}$ is troublesome due to its low solubility in organic solvents. There are several examples of re-crystallization, which mostly use water and ethanol [25]. Therefore, we used a method of double-filtration. The reaction mixture was cooled to room temperature and filtrated first with cold heptane to remove the unreacted starting materials. As a second step, hot methanol was used to isolate the product from the catalyst.

Comparing the obtained isolated yields with the specific surface area (SSA) of the catalyst, the specific surface area seemed to play no significant role in the outcome of the reaction. For example, the PdHAp2 and ZnHAp2 had the same SSA $\left(109 \mathrm{~m}^{2} / \mathrm{g}\right)$, but the isolated yields of the products differed greatly (Table 1, entries 6 and 7). This means that the cation used to modify the apatite is more important than the SSA value and influences the formation of the product to a greater extent. Nevertheless, the use of modified $\mathrm{Cu}-, \mathrm{Zn}-, \mathrm{Pd}-$ and MgHAp is made impossible by a more or less important release of such cations from the structureof the apatite into the solution during the reaction.

We explore an another way to enhance the efficiency of apatites as catalysts in the Biginelli reaction by tunning the basic properties of the apatite surfaces. The idea was to increase the surface hydroxyl group activity. Such an increase in the surface hydroxyl activity in the apatitic structure can be achieved by the presence of cations like $\mathrm{Sr}^{2+}$ (IR $1.18 \AA$ ) or $\mathrm{Ba}^{2+}$ (IR $1.35 \AA$ ) which are bigger than $\mathrm{Ca}^{2+}$ (IR $1.0 \AA$ ) and consequently less acidic, exalting the basicity of the surface hydroxyl ions located near them [32].

Then, the abilities of SrHAp, BaHAp and mixed SrBaHAp to catalyze the Biginelli reaction were tested. The reaction was conducted in refluxing methanol and the yields are calculated for isolated pure crystallized final products. The results obtained are presented in Table 4. 
Table 4. Calcium, Strontium and Barium Apatites catalyzed synthesis of different dihydropyrimidinones under reflux condition using methanol and toluene as solvent

\begin{tabular}{|c|c|c|c|c|c|c|}
\hline \multirow{2}{*}{ Entry } & \multirow{2}{*}{$\mathrm{R}$} & \multirow{2}{*}{ Solvent } & \multirow{2}{*}{ Samples } & \multirow{2}{*}{ Yield $(\%)$} & \multicolumn{2}{|c|}{ Melting point $(\mathrm{Mp})\left({ }^{\circ} \mathrm{C}\right)$} \\
\hline & & & & & Found & Reported \\
\hline \multirow{5}{*}{$4 \mathbf{a}$} & \multirow{5}{*}{$\mathrm{H}$} & \multirow{5}{*}{ Methanol } & HAp4 & 8 & \multirow{5}{*}{$200-202$} & \multirow{5}{*}{$198-200[48]$} \\
\hline & & & SrHAp & 5 & & \\
\hline & & & CaSrHAp & 12 & & \\
\hline & & & BaHAp & 65 & & \\
\hline & & & BaSrHAp & 35 & & \\
\hline \multirow{2}{*}{$4 b$} & \multirow{2}{*}{$\mathrm{OCH}_{3}$} & \multirow{2}{*}{ Methanol } & ВаHAp & 54 & \multirow{2}{*}{ 201-202 } & \multirow{2}{*}{ 201-202 [49] } \\
\hline & & & BaSrHAp & 30 & & \\
\hline \multirow{2}{*}{$4 c$} & \multirow{2}{*}{$\mathrm{N}\left(\mathrm{CH}_{3}\right)_{2}$} & \multirow{2}{*}{ Methanol } & BaHAp & 65 & \multirow{2}{*}{$256-258$} & \multirow{2}{*}{$256-257[49]$} \\
\hline & & & BaSrHAp & 40 & & \\
\hline \multirow{4}{*}{$4 d$} & \multirow{4}{*}{$\mathrm{NO}_{2}$} & & ВаHAp & 0 & \multirow{4}{*}{$205-208$} & \multirow{4}{*}{$207-209[50]$} \\
\hline & & Methanol & BaSrHAp & 37 & & \\
\hline & & & SrHAp & 0 & & \\
\hline & & Toluene & BaHAp & 0 & & \\
\hline \multirow{4}{*}{$4 f$} & \multirow{4}{*}{$\mathrm{F}$} & \multirow{3}{*}{ Methanol } & SrHAp & 0 & & \\
\hline & & & ВаHAp & 0 & & \\
\hline & & & BaSrHAp & 0 & & \\
\hline & & Toluene & BaHAp & 0 & & \\
\hline
\end{tabular}

SrHAp (5\% yield for $\mathbf{4 a}$ ) or mixed SrCaHAp (12\% yield for $\mathbf{4 a}$ ) are not better catalysts than CaHAp (8\% yield for $\mathbf{4 a}$ ). The better results are obtained for BaHAp when starting from benzaldehyde (65\% Yield), 4-methoxybenzaldehyde (54\% yield) and 4-dimethylaminobenzaldehyde (65\% yield). No reaction occurred using 4-fluorobenzaldehyde or 4-nitrobenzaldehyde as starting material. These results highlight that neutral or donor 4-substituant groups favor the reaction whereas attractive one disfavor the reaction. These results remain the same when changing the solvent from methanol to toluene. The results obtained using a mixed BaSrHAp are generaly not better than for pure BaHAp. The only exception is the nitro compounds, $\mathbf{4 c}$ obtained with a $37 \%$ yield.

\section{Conclusion}

In conclusion, we have developed and shown the use of apatites as catalysts in the Biginelli reaction. Actually, stoichiometric calcium apatites are not efficient catalysts for this reaction since they afford products in low yield and with a low reaction rate. However, under solvent-free conditions nonmodified HAp-s were efficient enough to catalyse the Biginelli reaction. In addition, the use of nonmodified catalysts avoids the release of cations in the solution. The catalyst could be repeatedly used 
in several consecutive runs. It could be activated simply by heating and used again without loss of activity. The simplicity of the procedure makes the protocol potentially useful for other HAp-catalysed reactions.

Using modified apatites obtained by substituting calcium ions with more acidic ones $(\mathrm{Mg}, \mathrm{Cu}$, $\mathrm{Zn}$ and Pd) enhance significantly the final yield in "Biginelli product". Nevertheless, leaching of such cations in the solution during the reaction process is often a resulting problem. The better results in yields, but not in reaction rate are obtained by using a stoichiometric barium apatite. We assume than the increase in activity of this apatite can be correlated with the enhancement of the $\mathrm{OH}$ activity at the surface of the material.

\section{Experimental section}

\subsection{General}

All chemicals were purchased from Aldrich Chemical Co and were used without further purification. ${ }^{1} \mathrm{H}$ NMR and ${ }^{13} \mathrm{C}$ NMR spectra were obtained from solution $\mathrm{CDCl}_{3}$ and DMSO-d6 with TMS as internal standard using BRUKER AVANCE III (400 MHz) spectrometer. Melting points were determined using a Stuart.SMP11 instrument. The infrared (IR) adsorption analysis were obtained using a Spectrum Two 104462 IR spectrophotometer equipped with a diamond Attenuated Total reflectance (ATR) setup in the range 4000-400 $\mathrm{cm}^{-1}$. The content of $\mathrm{Cu}^{2+}$ and $\mathrm{Zn}^{2+}$ ions in HAp before and after reaction was determined by Atomic Absorption Spectroscopy (AAS) after dissolution of the apatite in $\mathrm{HNO}_{3}$ solution. The content of $\mathrm{Pd}^{2+}$ in $\mathrm{HAp} 2$ before and after reaction was detected by energy-dispersive X-ray spectroscopy (EDX) carried out on Oxford Instruments INCA- Energy system using Penta FET x3 analyzer. Quantitative analysis was carried out using factory-defined standards. The phosphorus, magnesium and calcium contents were obtained by ICP-OES on a Horiba Jobin Yvon modele active. X-ray diffraction (XRD) analysis of catalysts were carried out by means of a X'Pert Pro Panalytical X-pert diffractometer using $\mathrm{Cu}-\mathrm{K} \alpha$ radiation $(\lambda=1.5418 \AA$, with $\theta-\theta$ geometry, equipped with an $X^{\prime}$ Celerator solid detector and a $\mathrm{Ni}$ filter). The $2 \theta$ range was from 20 to $70^{\circ}$ with a step size $\Delta 2 \theta=0.0167^{\circ}$. The experimental patterns were compared to standards compiled by the Joint Committee on Powder Diffraction and Standards (JCPDS cards) using the X'Pert High- Score Plus software [51]. Specific surface area (SSA) was determined by the BET-method (adsorptive gas $\mathrm{N}_{2}$, carrier gas He, heating temperature $150{ }^{\circ} \mathrm{C}$ ) with Costech instruments Sorbtometer KELVIN 1042.

ESI-MS experiments were carried out using a LTQ-Orbitrap XL from Thermo Scientific (Thermo Fisher Scientific, Courtaboeuf, France) and operated in positive ionization mode, with a spray voltage at $3.6 \mathrm{kV}$. Sheath and auxiliary gas were set at a flow rate of 45 and 15 arbitrary units (a.u.), respectively. Applied voltages were 20 and $70 \mathrm{~V}$ for the ion transfer capillary and the tube lens, respectively. The ion transfer capillary was held at $275^{\circ} \mathrm{C}$. Detection was achieved in the Orbitrap with 
a resolution set to 60,000 (at $\mathrm{m} / \mathrm{z} 400$ ) and a $\mathrm{m} / \mathrm{z}$ range between $110-1200$ in profile mode. Spectrum was analyzed using the acquisition software XCalibur 2.1 (Thermo Fisher Scientific, Courtaboeuf, France). The automatic gain control (AGC) allowed accumulation of up to $2.10^{5}$ ions for FTMS scans. Maximum injection time was set to $300 \mathrm{~ms}$ and $1 \mu \mathrm{scan}$ was acquired. $5 \mu \mathrm{L}$ was injected using a Thermo Finnigan Surveyor HPLC system (Thermo Fisher Scientific, Courtaboeuf, France) with a continuous infusion of methanol at $100 \mu \mathrm{L} \cdot \mathrm{min}^{-1}$.

\subsection{Synthesis of the catalysts}

\subsubsection{Synthesis of HAp}

The apatites were synthesised according to known wet precipitation methods [52]. For HAp1 synthesis, the starting materials were $\mathrm{CaO}$ and $\mathrm{H}_{3} \mathrm{PO}_{4}$. $\mathrm{CaO}$ was mixed with deionized water $(1 \mathrm{~g}$ in 30 $\mathrm{mL}$ ) under an $\mathrm{N}_{2}$ atmosphere with magnetic stirring for $1 \mathrm{~h}$ and then $0.4 \mathrm{M} \mathrm{H}_{3} \mathrm{PO}_{4}$ solution was added at a rate of $0.3 \mathrm{~mL} / \mathrm{min}$ with continuous mixing at room temperature. The mixing was continued for 24 $\mathrm{h}$ then the slurry mixture was filtrated and dried at $110^{\circ} \mathrm{C}$.

HAp2, HAp3 and HAp4 were synthesised by adding $\mathrm{Ca}\left(\mathrm{NO}_{3}\right)_{2}$ and $\left(\mathrm{NH}_{4}\right)_{2} \mathrm{HPO}_{4}$ solutions $(0.5$ $\mathrm{M}$ and $0.3 \mathrm{M}$, respectively) simultaneously with a rate of $5 \mathrm{~mL} / \mathrm{min}$ into water- $\mathrm{NH}_{4} \mathrm{OH}$ solution at $23{ }^{\circ} \mathrm{C}$ at a $\mathrm{Ca} / \mathrm{P}$ molar ratio of 1.67 (corresponding to a stoichiometric hydroxyapatite). The $\mathrm{pH}$ was maintained between 9 and 11 in the case of HAp2 and between 8 and 9 in the case of HAp3 by the discontinuous addition of concentrated aqueous $\mathrm{NH}_{3}$. The formed dispersion was continuously stirred for $3 \mathrm{~h}$, aged at $23{ }^{\circ} \mathrm{C}$ for $24 \mathrm{~h}$, then filtrated and washed several times with deionized water. HAp were dried at $110{ }^{\circ} \mathrm{C}$ under vacuum, and ground in agate mortar.

\subsubsection{Synthesis of SrHAp, CaSrHAp, BaHAp and BaSrHAp}

The synthesis of BaHAp, SrHAp, CaSrHAp and BaSrHAp were carried out by a double decomposition method [53]. In nitrogen atmosphere, a solution of different metal cations $\mathrm{Ca}\left(\mathrm{NO}_{3}\right)_{2} \cdot 4 \mathrm{H}_{2} \mathrm{O}, \mathrm{Ba}\left(\mathrm{NO}_{3}\right)_{2}$, or $\operatorname{Sr}\left(\mathrm{NO}_{3}\right)_{2}(0.2 \mathrm{M}, 150 \mathrm{~mL})$ was added dropwise to a solution of $\left(\mathrm{NH}_{4}\right)_{2} \mathrm{HPO}_{4}(0.2 \mathrm{M}, 250 \mathrm{~mL})$, maintained at boiling temperature, under stirring. The $\mathrm{pH}$ value of the mixture was adjusted to 10 with regular addition of $\mathrm{NH}_{4} \mathrm{OH}$. The resulting precipitate was maintained in contact with the reaction solution for $1 \mathrm{~h}$, then filtered and repeatedly washed with hot distilled water. The final product was dried at $120^{\circ} \mathrm{C}$ overnight.

\subsubsection{Synthesis of $\mathrm{Mg}, \mathrm{Cu}, \mathrm{Zn}$ and Pd modified HAp}


The Mg modified apatite (MgHAp) has been synthesized using the hydrothermal method [54]. A demineralized aqueous solution $(14 \mathrm{~mL}, 0.75 \mathrm{M})$ of a mixture of the two nitrates $\mathrm{Ca}\left(\mathrm{NO}_{3}\right)_{2} \cdot 4 \mathrm{H}_{2} \mathrm{O}$ and $\mathrm{Mg}\left(\mathrm{NO}_{3}\right)_{2} \cdot 6 \mathrm{H}_{2} \mathrm{O}$ in the desired proportions is added to a $\left(\mathrm{NH}_{4}\right)_{2} \mathrm{HPO}_{4}$ aqueous solution $(25 \mathrm{~mL}$, $0.25 \mathrm{M})$. The final $\mathrm{pH}$ of the solution is adjusted to 9 by adding a $\mathrm{NH}_{4} \mathrm{OH}$ solution $(\mathrm{d}=0.89,28 \%)$. The final mixture is transferred to an autoclave and is maintained there at $120^{\circ} \mathrm{C}$ for $20 \mathrm{~h}$. After filtration and washing using hot demineralized water, the final product is dried at $120^{\circ} \mathrm{C}$

The $\mathrm{Cu}$ and $\mathrm{Zn}$-modified apatites were obtained by mixing $100 \mathrm{mg}$ of the HAp3 with $50 \mathrm{~mL}$ of $\mathrm{Cu}\left(\mathrm{CH}_{3} \mathrm{COO}\right)_{2}$ solution $(0.01 \mathrm{M})$ and $\mathrm{HAp} 2$ with $50 \mathrm{~mL}$ of $\mathrm{Zn}\left(\mathrm{NO}_{3}\right)_{2}$ solution $(0.002 \mathrm{M})$, respectively. The suspension $(\mathrm{pH}=6)$ was stirred at $25^{\circ} \mathrm{C}$ for $24 \mathrm{~h}$. The obtained slurry was filtered, washed with deionised water, and dried overnight at $110^{\circ} \mathrm{C}$.

Pd-modified apatite (PdHAp) was obtained by mixing $200 \mathrm{mg}$ of the HAp2 with $250 \mathrm{~mL}$ of $\mathrm{Pd}\left(\mathrm{NO}_{3}\right)_{2} \cdot 2 \mathrm{H}_{2} \mathrm{O}$ solution $(0.001 \mathrm{M})$. The suspension $(\mathrm{pH}=5.4)$ was stirred at $25^{\circ} \mathrm{C}$ for $24 \mathrm{~h}$. The obtained slurry was filtered, washed with deionized water, and dried overnight at $110{ }^{\circ} \mathrm{C}$. The content of $\mathrm{Ca}$ and $\mathrm{P}$ of the apatites was measured by standard chemical analytical methods after dissolution of the sample in $\mathrm{HCl}(1: 1)$. Chemical composition and SSA of the synthesized apatites are shown in Table 5.

\subsection{Synthesis of 3,4-dihydropyrimidin-2(1H)-one}

A mixture of aldehyde $(10 \mathrm{mmol})$, ethyl acetoacetate $(10 \mathrm{mmol})$, urea $(10 \mathrm{mmol})$ and catalyst (2.5 mol\%) were mixed by stirring over a period of time shown in Table 1 . The experiment was performed at reflux conditions in the presence of solvents such as methanol, ethanol and toluene (12 $\mathrm{mL})$.

After the completion of the reaction (monitored by thin layer chromatography), the catalyst was separated from the reaction mixture by filtration and then the liquid part was poured into water. The obtained solid product was filtered and dried. The crude product was purified by recrystallization in methanol.

\subsection{Identification of the catalysts}

\subsubsection{Chemical composition and SSA of the HAp}

Table 5. Chemical composition and SSA of the apatites

\begin{tabular}{lll}
\hline Samples & $\begin{array}{l}\text { Atom ratio } \\
\left(\text { Cation }^{2+} / \mathrm{P}\right)\end{array}$ & \\
& &
\end{tabular}




\begin{tabular}{lll}
\hline HAp1 & 1.67 & 82.3 \\
HAp2 & 1.64 & 109 \\
HAp3 & 1.57 & 77.7 \\
HAp4 & 1.68 & 42 \\
SrHAp & 1.65 & 40 \\
BaHAp & 1.67 & 7 \\
BaSrHAp & 1.64 & 18 \\
CaSrHAp & 1.66 & 44 \\
MgHAp & 1.65 & 20 \\
\hline
\end{tabular}

\subsubsection{CaHAp Infra-red spectra}

FTIR ATR analysis of the products revealed slightly carbonated $\left(\sim 1 \% \mathrm{CO}_{2}\right)$ hydroxyapatites. The sorption of $\mathrm{Mg}, \mathrm{Cu}, \mathrm{Zn}$ or Pd ions did not change the structure of apatite. IR spectra for these apatites are shown in Figure 1 and 2. All the IR spectra displayed the characteristic absorption bands of calcium apatite [55]. The $\mathrm{P}-\mathrm{O}$ bands in the range $1089.2-1026.0 \mathrm{~cm}^{-1}$ and $600.7-661.4 \mathrm{~cm}^{-1}$ are attributed to the asymmetric stretching and bending vibrations of $\mathrm{PO}_{4}{ }^{3-}$ respectively. The peaks ate $962.5 \mathrm{~cm}^{-1}$ and $471.7 \mathrm{~cm}^{-1}$ correspond to the symmetric stretching and bending vibrations of $\mathrm{PO}_{4}{ }^{3-}$ respectively. The libration hydroxyl band is observed at $630.7 \mathrm{~cm}^{-1}$ and the $-\mathrm{OH}$ stretching vibration at $3570 \mathrm{~cm}^{-1}[56,57]$.

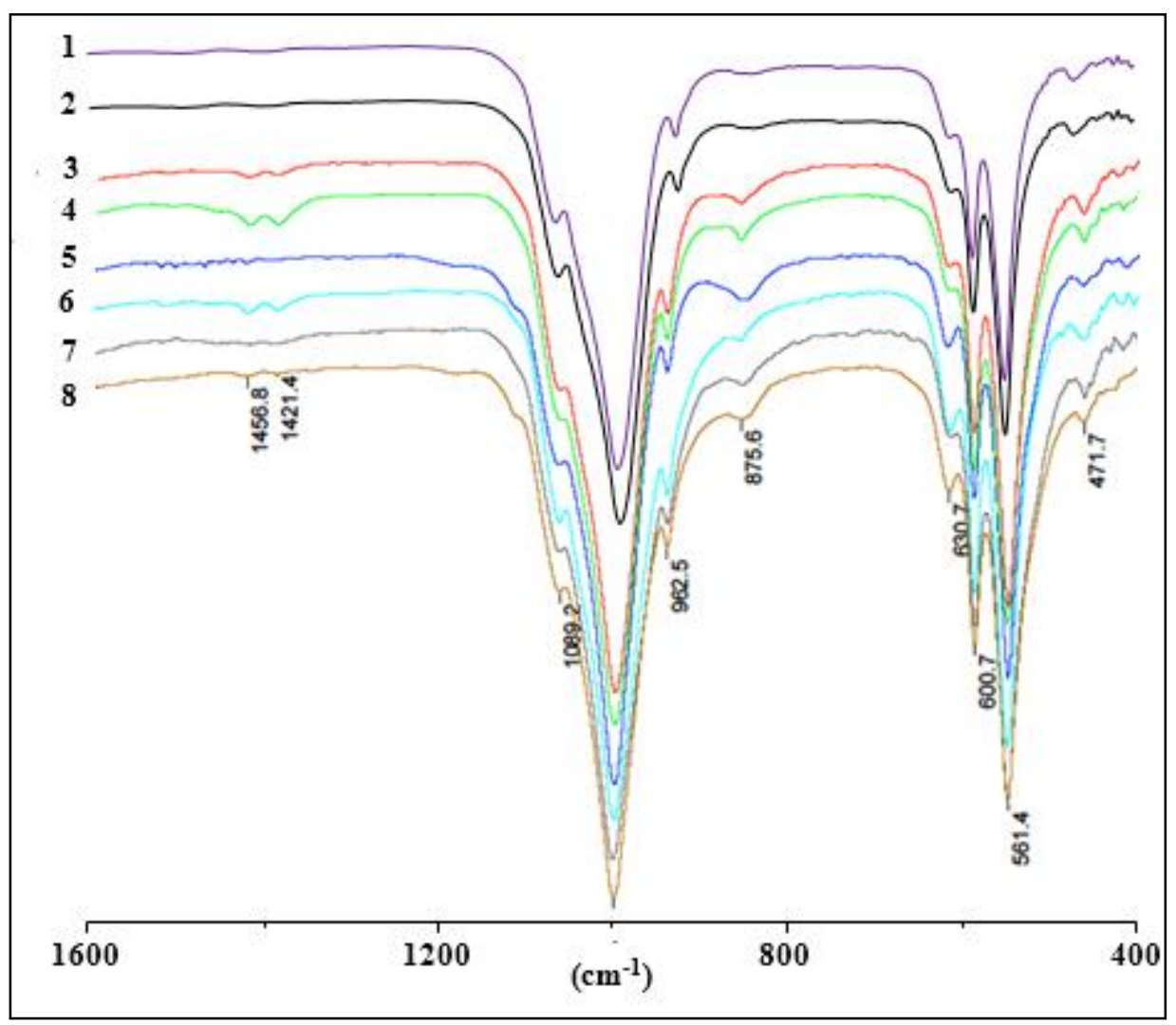


Fig.1. IR spectra of HAp1 (1), HAp2 (2), HAp3 (3), HAp4 (4), CuHAp3 (5), ZnHAp2 (6), MgHAp (7) and PdHAp2 (8)

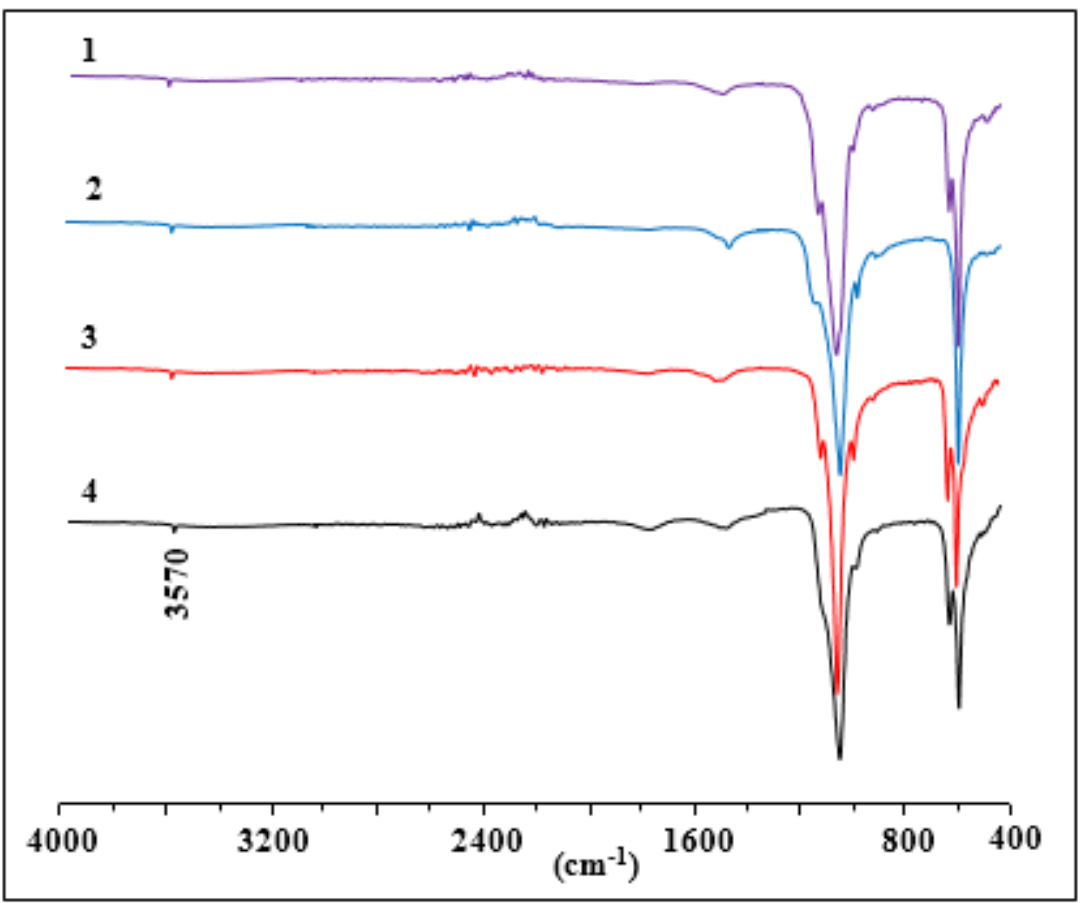

Fig.2. IR spectra of CaSrHAp (1), SrHAp (2), BaHAp (3) and BaSrHAp (4)

\subsubsection{X-ray data}

Powder X-ray diffraction analysis of the samples HAp4, CaSrHAp, SrHAp, BaHAp and MgHAp indicates single phase and good crystallinity. The X-ray diffraction patterns are shown in Figure 3. All the peaks of every motive were indexed in the hexagonal system ( $\mathrm{P}_{3} / \mathrm{m}$ space group) based on the hydroxyapatite model $\mathrm{Ca}_{10}\left(\mathrm{PO}_{4}\right)_{6}(\mathrm{OH})_{2}$ (JCPDS 01-084-1998). 


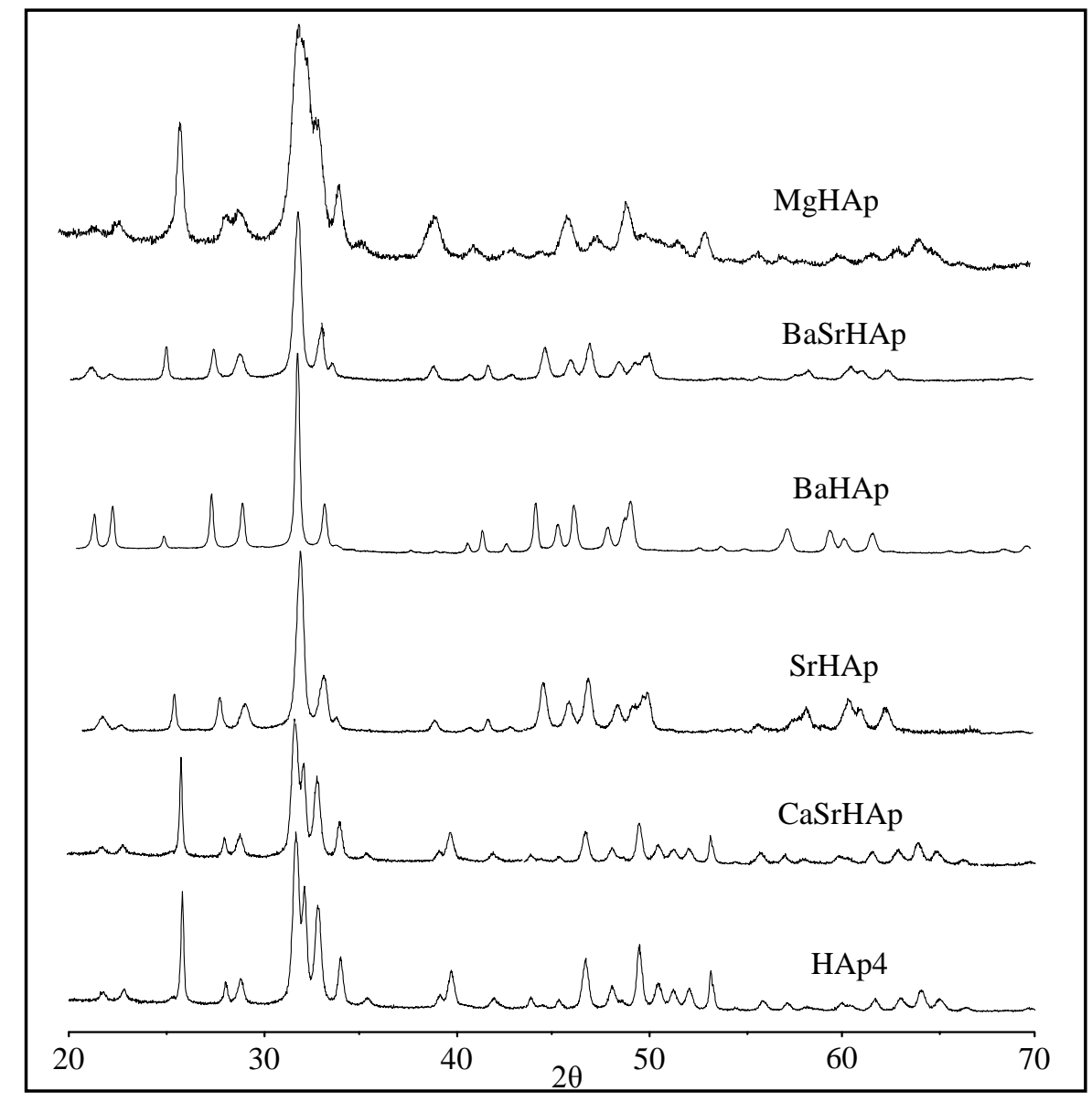

Fig.3. X-ray diffractograms for HAp4, CaSrHAp, SrHAp, BaHAp an MgHAp

4.5. Spectral data of the obtained products $\mathrm{R}=\mathrm{H}(4 \mathrm{a}), \mathrm{O}-\mathrm{CH}_{3}(4 \mathrm{~b}), \mathrm{N}\left(\mathrm{CH}_{3}\right)_{2}(4 \mathrm{c})$, and $\mathrm{NO}_{2}(4 \mathrm{~d})$

Ethyl 6-methyl-2-oxo-4-phenyl-1,2,3,4-tetrahydropyrimidine-5-carboxylate (4a)

${ }^{1} \mathrm{H} \mathrm{NMR}\left(\mathrm{CDCl}_{3}\right): \delta=7.62(\mathrm{~s}, 1 \mathrm{H}, \mathrm{NH}), 7.24\left(\mathrm{~m}, 5 \mathrm{H}, \mathrm{C}_{6} \mathrm{H}_{5}\right), 5.51(\mathrm{~s}, 1 \mathrm{H}, \mathrm{NH}), 5.31(\mathrm{~s}, 1 \mathrm{H}, \mathrm{CH}), 4.02$ (q, J=7.2Hz, 2H, $\left.\mathrm{OCH}_{2} \mathrm{CH}_{3}\right), 2.26\left(\mathrm{~s}, 3 \mathrm{H}, \mathrm{CH}_{3}\right), 1.05\left(\mathrm{t}, \mathrm{J}=7.2 \mathrm{~Hz}, 3 \mathrm{H}, \mathrm{CH}_{3}\right)$.

${ }^{13} \mathrm{C} \mathrm{NMR}\left(\mathrm{CDCl}_{3}\right): \delta=165.6,153.2,146.2,143.7,128.7,127.9,126.5,101.3,60.0,55.7,18.6,14.1$. IR: $\mathrm{cm}^{-1} 3230,3110,1725,1700,1638$.

HRMS (ESI, [M+Na] $]^{+}$: $\mathrm{C}_{14} \mathrm{H}_{16} \mathrm{~N}_{2} \mathrm{O}_{3} \mathrm{Na}$, Calculated 283.1053, Experimental: 283.1050; $1.1 \mathrm{ppm}$.

Ethyl 4-(4-methoxyphenyl)-6-methyl-2-oxo-4-phenyl-1,2,3,4-tetrahydropyrimidine-5-carboxylate (4b) 
${ }^{1} \mathrm{H}$ NMR $\left(\mathrm{CDCl}_{3}\right): \delta=8.06(\mathrm{~s}, 1 \mathrm{H}, \mathrm{NH}), 7.18-6.72\left(\mathrm{~m}, 4 \mathrm{H}, \mathrm{C}_{6} \mathrm{H}_{4}\right), 5.66(\mathrm{~s}, 1 \mathrm{H}, \mathrm{NH}), 5.25(\mathrm{~s}, 1 \mathrm{H}, \mathrm{CH})$, 3.98 (q, J=7.2Hz, 2H, $\mathrm{OCH}_{2} \mathrm{CH}_{3}$ ), 3.71 (s, 3H, $\mathrm{OCH}_{3}$ ), 2.26 (s, 3H, $\left.\mathrm{CH}_{3}\right), 1.08$ (t, J=7.2Hz, 3H, $\mathrm{CH}_{3}$ ). ${ }^{13} \mathrm{C} \mathrm{NMR}\left(\mathrm{CDCl}_{3}\right): \delta=165.6,159.2,153.2,145.8,136.1,127.8,113.9,101.6,59.9,55.3,55.2,18.6$, 14.1.

IR: $\mathrm{cm}^{-1} 3240,3110,1725,1710,1655$.

HRMS (ESI, [M+Na] ${ }^{+}$): $\mathrm{C}_{14} \mathrm{H}_{28} \mathrm{~N}_{2} \mathrm{O}_{4} \mathrm{Na}$, Calculated 313,1159, Experimental: 313.1155; 1.2 ppm. Ethyl 4-(4-(dimethylamino)phenyl)-6-methyl-2-oxo-4-phenyl-1,2,3,4-tetrahydropyrimidine-5carboxylate (4c)

${ }^{1} \mathrm{H}$ NMR $\left(\mathrm{CDCl}_{3}\right): \delta=7.21(\mathrm{~s}, 1 \mathrm{H}, \mathrm{NH}), 7.10\left(\mathrm{~d}, \mathrm{~J}=8.2 \mathrm{~Hz}, 2 \mathrm{H}, \mathrm{C}_{6} \mathrm{H}_{4}\right), 6.58\left(\mathrm{~d}, \mathrm{~J}=8.3 \mathrm{~Hz}, 2 \mathrm{H}, \mathrm{C}_{6} \mathrm{H}_{4}\right)$, $5.28(\mathrm{~s}, 1 \mathrm{H}, \mathrm{NH}), 5.22(\mathrm{~s}, 1 \mathrm{H}, \mathrm{CH}), 4.00\left(\mathrm{q}, \mathrm{J}=7.2 \mathrm{~Hz}, 2 \mathrm{H}, \mathrm{OCH}_{2} \mathrm{CH}_{3}\right), 2.85\left(\mathrm{~s}, 6 \mathrm{H}, \mathrm{N}\left(\mathrm{CH}_{3}\right)_{2}\right), 2.25(\mathrm{~s}$, $\left.3 \mathrm{H}, \mathrm{CH}_{3}\right), 1.12\left(\mathrm{t}, \mathrm{J}=7.2 \mathrm{~Hz}, 3 \mathrm{H}, \mathrm{CH}_{3}\right)$.

${ }^{13} \mathrm{C}$ NMR (DMSO-d6): $\delta=165.9,152.8,150.0,147.7,133.2,127.4,112.4,100.4,59.4,53.9,43.4$, 18.2, 14.5 .

IR: $\mathrm{cm}^{-1} 3340,3190,2976,1706,1648,1528$.

HRMS (ESI, $[\mathrm{M}+\mathrm{H}]^{+}$): $\mathrm{C}_{16} \mathrm{H}_{22} \mathrm{~N}_{3} \mathrm{O}_{3}$, Calculated 304.1656, Experimental: 304.1653; 0.9 ppm.

Ethyl 4-(4-nitrophenyl)-6-methyl-2-oxo-4-phenyl-1,2,3,4-tetrahydropyrimidine-5-carboxylate (4d) ${ }^{1} \mathrm{H} \mathrm{NMR}\left(\mathrm{CDCl}_{3}\right): \delta=8.12\left(\mathrm{~d}, \mathrm{~J}=9.6 \mathrm{~Hz}, 2 \mathrm{H}, \mathrm{C}_{6} \mathrm{H}_{4}\right), 7.87(\mathrm{~s}, 1 \mathrm{H}, \mathrm{NH}), 7.40\left(\mathrm{~d}, \mathrm{~J}=9.6 \mathrm{~Hz}, 2 \mathrm{H}, \mathrm{C}_{6} \mathrm{H}_{4}\right)$, $5.49(\mathrm{~s}, 1 \mathrm{H}, \mathrm{NH}), 5.42(\mathrm{~s}, 1 \mathrm{H}, \mathrm{CH}), 4.02\left(\mathrm{q}, \mathrm{J}=7.2 \mathrm{~Hz}, 2 \mathrm{H}, \mathrm{OCH}_{2} \mathrm{CH}_{3}, 2.30\left(\mathrm{~s}, 3 \mathrm{H}, \mathrm{CH}_{3}\right), 1.12\right.$ (t, $\left.\mathrm{J}=7.2 \mathrm{~Hz}, 3 \mathrm{H}, \mathrm{CH}_{3}\right)$.

${ }^{13} \mathrm{C} \mathrm{NMR}\left(\mathrm{CDCl}_{3}\right): \delta=165.1,152.6,150.3,147.5,146.9,127.5,124.1,100.6,60.4,55.2,18.9,14.1$. IR: $\mathrm{cm}^{-1} 3320,3085,2986,1730,1694,1588$.

HRMS (ESI, [M+Na] $]^{+}$: $\mathrm{C}_{14} \mathrm{H}_{15} \mathrm{~N}_{3} \mathrm{O}_{5} \mathrm{Na}$, Calculated 328.0899, Experimental: 328.0899; 1.5 ppm.

\section{Acknowledgments}

Authors thank the University of Monastir (Tunisia); the University Pierre and Marie Curie (France) and CNRS (France); the Tallinn University of Technology (Estonia). This work was supported by institutional research funding IUT (19-32) of the Estonian Ministry of Education and Research and EU European Regional Development Fund (3.2.0101.08-0017). Parrot program 2013-2014, No. 29519 PK is also acknowledged.

\section{References}


[1] J.C. Elliot, Structure and Chemistry of the Apatites and Other Calcium Ortho-phosphates. First Ed., Elsevier, Amsterdam, 1994.

[2] C. Rey, C. Combes, C. Drouet, D. Grossin, In: Comprehensive Biomaterials; P. Ducheyne, K. Healy, D. Hutmacher, D.E. Grainger, J. Kirkpatrick, J. Eds. Elsevier, 1 (2011) 187-221.

[3] J. Gomez-Morales, M. Iafisco, J. M. Delgado-Lopez, S. Sarda, C. Drouet, Progress on the preparation of nanocrystalline apatites and surface characterization: Overview of fundamental and applied aspects. Cryst. Growth Charact. Mater. 59(1) (2013) 1-46.

[4] S. Sebti, M. Zahouily, H. B. Lazrek, J. A. Mayoral, D. J. Macquerie, Phosphates: New generation of liquid-phase heterogeneous catalysts in organic chemistry, Curr. Org. Chem. 12 (2008) 203-232.

[5] K. Kaneda, T. Mizukagi, Development of concerto metal catalysts using apatite compounds for green organic synthesis. Energy Environ. Sci. 2 (2009) 655-673.

[6] M. Gruselle, Apatites A new family of catalysts in organic synthesis. J. Organomet. Chem. 793 (2015) 93-101.

[7] M. Gruselle, K. Tõnsuaadu, Tunable calcium-apatites as solid catalysts for classical organic reactions. Current Org. Chem. 21 (2017) 688-697.

[8] P. Biginelli, Ueber Aldehyduramide des Acetessigäthers, Chem. Ber. 24 (1891) 1317-1319.

[9] P. Biginelli, Ueber Aldehyduramide des Acetessigäthers. II, Chem. Ber. 24 (1891) 2962-2967.

[10] S. Sandhu, J. S. Sandhu, Past, present and future of the Biginelli reaction: a critical perspective, ARKIVOC, 2012, 66-133.

[11] Q. Haijun, L. Xuejian, M. Fan. L. Xufeng, Efficient synthesis of dihydropyrimidinones via a three-component Biginelli-type reaction of urea, alkylaldehyde and arylaldehyde, Beilstein, J. Org. Chem. 9 (2013) 2846-2851.

[12] J. P. Wan, Y. Liu, Synthesis of Dihydropyrimidinones and Thiones by Multicomponent Reactions: Strategies Beyond the Classical Biginelli Reaction, Synthesis, 42 (2010) 3943-3953.

[13] J. H. Clark, D.J. Macquarrie, J. Sherwood, The combined role of catalysis and solvent effects on the biginelli reaction: improving efficiency and sustainability, Chem. Eur. J. 19 (2013) 5174-5182.

[14] N. Gangwar, V.K. Kasana, 3,4-Dihydropyrimidin-2(1H)-one derivatives: Organocatalysed microwave assisted synthesis and evaluation of their antioxidant activity, Med. Chem. Res. 21 (2012) 4506-4511.

[15] C. O. Kappe, O. V. Shishkin, G. Uray, P. Verdino, X-Ray Structure, Conformational Analysis, Enantioseparation, and Determination of Absolute Configuration of the Mitotic Kinesin Eg5 Inhibitor Monastrol, Tetrahedron, 56 (2000) 1859-1862. 
[16] F. Ali, K.M. Khan, U. Salar, S. Iqbal, M. Taha, N. Ismail, S. Perveen, A. Wadood, M. Ghufran, B. Ali, Dihydropyrimidones: As novel class of $\beta$ - glucuronidase inhibitors, Bioorg. Med. Chem. 24 (2016) 3624-3635 .

[17] M. Arjun, D. Sridhar, M. Adharvana Chari, M. Sarangapani, You have full text access to this contentAn efficient Biginelli one-pot synthesis of new benzoxazole-substituted dihydropyrimidinones and thiones catalysed by alumina-supported trifluoromethane sulfonic acid under solvent free conditions, J. Heterocyclic Chem. 46 (2009) 119-123.

[18] G. R. Chaudhary, P. Bansal, S.K. Mehta, Recyclable CuS quantum dots as heterogeneous catalyst for Biginelli reaction under solvent free conditions, Chem. Engineering J. 243 (2014) 217-224. [19] A. K. Mitra, K. Banerjee, Clay catalysed synthesis of dihydropyrimidinones under solvent-free conditions, Synlett. 10 (2003) 1509-1511.

[20] Z. L. Shen, X. P. Xu, S. J. Ji, Brønsted Base-Catalyzed One-Pot Three-Component BiginelliType Reaction: An Efficient Synthesis of 4, 5, 6-Triaryl-3,4-dihydropyrimidin-2(1H)-one and Mechanistic Study J. Org. Chem. 75 (2010) 1162-.1167.

[21] P. Rajentral, C. Jagdish, B. Avul, Review biginelli reaction. Reagent support based approaches World, J. Pharm. Pharma. Sci. 5 (2016) 419-432.

[22] M. Puripat, R. Ramozzi, M. Hatanaka, W. Parasuk, V. Parasuk, K. Morokuma, The biginelli reaction is a urea-catalyzed organocatalutic multicomponent reaction, J. Org. Chem. 80 (2015) 69596967.

[23] C.O. Kappe, A reexamination of the Mechanism of the Biginelli Dihydropyrimidine Synthesis. Support for an N-Acyliminium Ion Intermediate, J. Org. Chem. 62 (1997) 7201-7204.

[24] C. O. Kappe, Biologically active dihydropyrimidones of the Biginelli type a literature survey, Eur. J. Med. Chem. 35 (2000) 1043-1052.

[25] M. Küçükislamoğlu, S. Beşoluk, M. Zengin, M. Arslan, M. Nebioğlu, An efficient one-pot synthesis of dihydropyrimidinones catalyzed by zirconium hydrogen phosphate under solvent-free conditions, Turk. J. Chem. 2010, 34, 411-416.

[26] M. Kargar, R. Hekmatshoar, A. Mostashari, Z. Hashemi, Efficient and green synthesis of 3,4dihydropyrimidin-2(1H)-ones/thiones using imidazol-1-yl-acetic acid as a novel, reusable and watersoluble organocatalyst, Catal. Comm. 15 (2011) 123-126.

[27] N. A. Liberto, S.P. Silva, A. Fátima, S.A. Fernandes, $\beta$-Cyclodextrin-assisted synthesis of Biginelli adducts under solvent-free conditions, Tetrahedron, 69 (2013) 8245-8249.

[28] S. Sumathi, G. Buvaneswari, Synthesis of apatite structure based $\mathrm{BiNaCa}_{3}\left(\mathrm{PO}_{4}\right)_{3} \mathrm{OH}$ and its application for condensation reaction, Ceram. Int. 38 (2012) 3547-3552. 
[29] H. El Badaoui, F. Bazi, S. Sokori, S. Boulaajaj, H.B. Lazrek, S. Sebti, One-pot synthesis of 3,4dihydropyrimidin-2(1H)-ones using $\mathrm{ZnCl}_{2}, \mathrm{CuCl}_{2}, \mathrm{NiCl}_{2}$ and $\mathrm{CoCl}_{2}$ doped hydroxyapatite, Lett. Org. Chem. 2 (2005) 561-565.

[30] H. El Badaoui, F. Bazi, R. Tahir, H. B. Lazrek, S. Sebti, Synthesis of 3,4-dihydropyrimidin-2ones catalysed by fluorapatite doped with metal halides, Catal. Comm. 6 (2005) 455-458.

[31] L. Garcia Rodenas, J.M. Palacios, M.C. Apella, P.J. Morando, M. A. Blesa, Surface properties of various powdered hydroxyapatites, J. Colloid Interface Sci. 290 (2005) 145-154.

[32] A. Venugopal, M. S. Scurrell, Hydroxyapatite as a novel support for gold and ruthenium catalysts: Behaviour in the water gas shift reaction, Appl. Catal. A: Gen. 245 (2003) 137-147.

[33] K. Mori, T. Hara, T. Mizugaki, K. Ebitani, K. Kaneda, Hydroxyapatite-Bound Cationic Ruthenium Complexes as Novel Heterogeneous Lewis Acid Catalysts for Diels-Alder and Aldol Reactions, J. Am. Chem. Soc. 125 (2003) 11460-11461.

[34] S. Sebti, R. Tahir, R. Nazih, S. Boulaajaj, Comparison of different Lewis acid supported on hydroxyapatite as new catalysts of Friedel-Crafts alkylation, Appl. Catal. A: Gen. 218 (2001) 25-30.

[34] Y. Maeda, Y. Washitake, T. Nishimura, K. Iwai, T. Yamauchi, S. Uemura, Calcium phosphatevanadate apatite (CPVAP)-catalyzed aerobic oxidation of propargylic alcohols with molecular oxygen, Tetrahedron, 60 (2004) 9031-9036.

[36] E. G. Rodrigues, T. C. Keller, S. Mitchell, J. Pérez-Ramirez, Hydroxyapatite, an exceptional catalyst for the gas-phase deoxygenation of bio-oil by aldol condensation, Green Chem. 16 (2014) 4870-4874.

[37] M. Gruselle, T. Kanger, R. Thouvenot, A. Flambard, K. Kriis, V. Mikli, R. Traksmaa, B. Maaten, K. Tõnsuaadu, Calcium Hydroxyapatites as Efficient Catalysts for the Michael CC Bond Formation, ACS Cat. 1 (2011) 1729-1733.

[38] B. Maaten, J. Moussa, C. Desmarets, P. Gredin, P. Beaunier, T. Kanger, K. Tõnsuaadu, D. Villemin, M. Gruselle, Cu-modified hydroxy-apatite as catalyst for Glaser-Hay C-C homo- coupling reaction of terminal alkynes, J. Mol. Cat. A: Chem. 393 (2014) 112-116.

[39] J.W. Jaworski, S. Cho, Y. Kim, J.H. Jung, H.S. Jeon, B.K. Min, K.Y. Kwon, Hydroxyapatite supported cobalt catalysts for hydrogen generation, J. Colloid Interface Sci. 394 (2013) 401-408.

[40] Y. Masuyama, K. Yoshikawa, N. Suzuki, K. Hara, A. Fukuoka, Hydroxyapatite-supported copper (II)-catalyzed azide-alkyne [3+2] cycloaddition with neither reducing agents nor bases in water, Tetrahedron Lett. 52 (2011) 6916-6918.

[41] Z. Opre, J. D. Grundwaldt, M. Maciejewski, D. Ferri, T. Mallat, A. Baiker, Promoted Ruhydroxyapatite: designed structure for the fast and highly selective oxidation of alcohols with oxygen, J. Catal. 230 (2005) 406-419. 
[42] K. Mori, S. Kanai, T. Hara, T. Mizugaki, K. Ebitani, K. Jitsukawa, K. Kaneda, Development of Ruthenium-Hydroxyapatite-Encapsulated Superparamagnetic $\gamma-\mathrm{Fe}_{2} \mathrm{O}_{3}$ Nanocrystallites as an Efficient Oxidation Catalyst by Molecular Oxygen, Chem. Mater. 19 (2007) 1249-1256.

[43] Y. Xu, F.W. Schwartz, Sorption of $\mathrm{Zn}^{2+}$ and $\mathrm{Cd}^{2+}$ on hydroxyapatite surfaces, Environ. Sci. Technol. 28 (1994) 1472-1480.

[44] K. Mori, M. Oshiba, T. Hara, T. Mizugaki, K. Ebitani, K. Kaneda, Creation of monomeric La complexes on apatite surfaces and their application as heterogeneous catalysts for Michael reactions, New J. Chem. 30 (2006) 44-52.

[45] R. D. Shannon, Revised effective ionic radii and systematic studies of interatomic distances in halides and chalcogenides, Acta Cryst. A 32 (1976) 751-767.

[46] K. Viipsi, S. Sjöberg, K. Tõnsuaadu, A. Shchukarev, Hydroxy- and fluorapatite as sorbents in $\mathrm{Cd}(\mathrm{II})-\mathrm{Zn}$ (II) multi-component solutions in the absence/presence of EDTA, J. Hazardous Mat. 252253 (2013) 91-98.

[47] M. Sljivic, I. Smiciklas, I. Plecas, M. Mitric, The influence of equilibration conditions and hydroxyapatite physico-chemical properties onto retention of $\mathrm{Cu}^{2+}$, Chem. Eng. 148 (2009) 80-88.

[48] Y. Yu, D. Liu, C. Liu, G. Luo, One-pot synthesis of 3,4-dihydropyrimidin-2(1H)-ones using chloroacetic acid as catalyst, Bioorg. Med. Chem. Lett. 17 (2007) 3508-3510.

[49] K. Folkers, H. Adkins, The catalytic hydrogenation of esters to alcohols, J. Am. Chem. Soc. 154 (1932) 1145-1154.

[50] G. H. Mahdavinia, H. Sepehrian, MCM-41 anchored sulfonic acid (MCM-41-R-SO $\left.{ }_{3} \mathrm{H}\right)$ : A mild, reusable and highly efficient heterogeneous catalyst for the Biginelli reaction, Cin. Chem. Lett. 19 (2008) 1435-1439.

[51] PANalytical X'Pert Higth Score Plus version 2.0.

[52] M. Sadat-Shojai, M. T. Khorasani, E. Dinpanah Khoshdargi, A. Jamshidi, Synthesis methods for nanosized hydroxyapatite with diverse structures, Acta Biomater. 9 (2013) 7591-7621.

[53] E. Boanini, M. Fini, M. Gazzano, A. Bigi, Hydroxyapatite Nanocrystals Modified with Acidic Amino Acids, Eur. J. Inorg. Chem. 23 (2006) 4821-4826

[54] A. Bigi, G. Falini, E. Foresti, M. Gazzano, A. Ripamonti, N. Roveri, Magnesium influence on hydroxyapatite cristallization, J. Inorg. Biochem. 49 (1993) 69-78.

[55] S. Shanmugam, B. Gopal, Copper substituted hydroxyapatite and fluorapatite: synthesis, characterization and antimicrobial properties, Ceram. Int. 40 (2014) 15655-15662.

[56] V. Stanic, D. Janackovic, S. Dimitrijevic, S.B. Tanaskovic, M. Mitric, M.S. Pavlovic, A. Krstic, D. Jovanovic, S. Raicevic, Synthesis of antimicrobial monophase silver-doped hydroxyaaptite nanopowder for bone tissue engineering, Appl. Surf. Sci. 257 (2011) 4510-4518. 
[57] A. Hadrich, A. Lautie, T. Mhiri, Vibrational study and fluorescence bands in the FT-Raman spectra of $\mathrm{Ca}_{10-\mathrm{x}} \mathrm{Pb}_{\mathrm{x}}\left(\mathrm{PO}_{4}\right)_{6}(\mathrm{OH})_{2}$ compounds, Spectrochim. Acta A 57 (2001) 1673-1681. 